\title{
The effect of two types of memory training on subjective and objective memory performance in healthy individuals aged 55 years and older: a randomized controlled trial.
}

Citation for published version (APA):

Valentijn, S. A. M., van Hooren, S. A. H., Bosma, J. H. A., Touw, D. M., Jolles, J., van Boxtel, M. P. J., \& Ponds, R. W. H. M. (2005). The effect of two types of memory training on subjective and objective memory performance in healthy individuals aged 55 years and older: a randomized controlled trial. Patient Education and Counseling, 57(1), 106-114. https://doi.org/10.1016/j.pec.2004.05.002

Document status and date:

Published: 01/01/2005

DOI:

10.1016/j.pec.2004.05.002

Document Version:

Publisher's PDF, also known as Version of record

Please check the document version of this publication:

- A submitted manuscript is the version of the article upon submission and before peer-review. There can be important differences between the submitted version and the official published version of record. People interested in the research are advised to contact the author for the final version of the publication, or visit the DOI to the publisher's website.

- The final author version and the galley proof are versions of the publication after peer review.

- The final published version features the final layout of the paper including the volume, issue and page numbers.

Link to publication

\footnotetext{
General rights rights.

- You may freely distribute the URL identifying the publication in the public portal. please follow below link for the End User Agreement:

www.umlib.nl/taverne-license

Take down policy

If you believe that this document breaches copyright please contact us at:

repository@maastrichtuniversity.nl

providing details and we will investigate your claim.
}

Copyright and moral rights for the publications made accessible in the public portal are retained by the authors and/or other copyright owners and it is a condition of accessing publications that users recognise and abide by the legal requirements associated with these

- Users may download and print one copy of any publication from the public portal for the purpose of private study or research.

- You may not further distribute the material or use it for any profit-making activity or commercial gain

If the publication is distributed under the terms of Article 25fa of the Dutch Copyright Act, indicated by the "Taverne" license above, 


\title{
The effect of two types of memory training on subjective and objective memory performance in healthy individuals aged 55 years and older: a randomized controlled trial
}

\author{
Susanne A.M. Valentijn ${ }^{\mathrm{a}, *}$, Susan A.H. van Hooren ${ }^{\mathrm{a}}$, Hans Bosma ${ }^{\mathrm{b}}$, Dory M. Touw ${ }^{\mathrm{a}}$, \\ Jelle Jolles ${ }^{\text {a }}$, Martin P.J. van Boxtel ${ }^{\text {a }}$, Rudolf W.H.M. Ponds ${ }^{\text {a }}$ \\ a Department of Psychiatry and Neuropsychology, European Graduate School of Neuroscience (Euron), Maastricht University, \\ P.O. Box 616, 6200 MD Maastricht, The Netherlands \\ ${ }^{\mathrm{b}}$ Department of Health Care Studies, Care and Public Health Research Institute, Maastricht University, The Netherlands
}

Received 5 August 2003; received in revised form 5 May 2004; accepted 6 May 2004

\begin{abstract}
The objective of the study was to examine the effectiveness of two types of memory training (collective and individual), compared to control (waiting list), on memory performance. Participants were 139 community-dwelling older individuals recruited through media advertisements asking for people with subjective memory complaints to participate in a study. Data were collected at baseline, and at 1 week and 4 months after the intervention. Training efficacy was assessed using measures of subjective and objective memory performance. After the intervention, participants in the collective training group reported more stability in memory functioning and had fewer feelings of anxiety and stress about memory functioning. In addition, positive effects were found on objective memory functioning. Compared with the other two groups, the collective training group participants had an improved recall of a previously learned word list. Compared to controls, participants in the individual training group reported fewer feelings of anxiety and stress in relation to memory functioning.

(C) 2004 Elsevier Ireland Ltd. All rights reserved.
\end{abstract}

Keywords: Memory; Intervention; Memory self-efficacy; Aging

\section{Introduction}

Elderly individuals often complain about their memory and are concerned that this perceived memory loss might lead to degenerative disorders such as Alzheimer's Disease $[1,2]$. A decline in memory functioning in old age might explain in part subjective memory complaints [3-5]. However, this explanation is not adequate because complaints of memory loss are not always associated with an actual decline in objective memory function [6-10]. Research shows that memory complaints are determined by several other factors besides objective memory performance $[11,12]$. The knowledge, beliefs, and perceptions people have about their own memory functioning and the memory system in general, termed 'metamemory', are considered an important factor [2,13-15]. Metamemory covers several dimensions that are relevant to everyday memory functioning. One of these dimensions, 'Memory Self-Efficacy' (MSE), can be defined

\footnotetext{
* Corresponding author. Tel.: +31 43 3875572; fax: +31 433884092. E-mail address: s.valentijn@np.unimaas.nl (S.A.M. Valentijn).
}

as the level of confidence a person has in the effectiveness of his or her own memory in different situations [16]. MSE is considered an important moderator of changes in memory functioning and can effect memory performance through cognitive, affective, and motivational processes $[17,18]$. For example, low expectations of successful memory functioning could lower motivation to achieve a good performance or could even cause avoidance of situations that call on memory. This negative influence could lead to a poorer memory performance and in turn reinforces the negative memory beliefs elderly have [19].

We designed a training program to improve objective memory and MSE. This program emphasizes how MSE works in relation to everyday memory performance. Participants are asked to actively register memory failures and successes in a dairy, to help them to gain insight into their memory functioning and to analyze their everyday memory problems. In addition, memory skills are trained by teaching the participants internal (repeating, visualization, making associations) and external (habits, agenda, people around you) memory strategies. Another important aspect of this training program is education on how the memory works in old 
age. Educating elderly people on how memory works and about the difference between normal and pathological aging are indispensable aspects of memory training. Other important aspects essential to optimal memory functioning, such as time, attention, concentration, good vision, and hearing are also discussed in depth [20].

To our knowledge, there have been few studies evaluating intervention programs focused on influencing and adjusting maladaptive beliefs about memory performance, combined with memory skills training [21]. Furthermore, most studies evaluated group-training programs. Group sessions are known to have a comforting and motivating effect because people can share problems with a relevant peer group [22]. However, self-taught memory-training programs are also an effective form of memory intervention [23-25], and are advantageous in that a large group of subjects can be reached in a fairly inexpensive way. Moreover, self-taught memory-training programs have some practical advantages, such as the fact that participants do not have to go to the training at fixed times and have the opportunity to study at their own speed. Therefore, we offered the intervention as a collective training program and as an individual self-taught training program, based on a handbook about memory functioning in daily life, and which contained the essentials of the collective training intervention.

The aim of the present study was to examine the effectiveness of these two forms of our memory-training program in comparison with control, in improving memory performance in a large group of community-dwelling older individuals.

\section{Methods}

\subsection{Participants}

All participants were older people recruited through media advertisements asking for people with subjective memory complaints to participate in a study. Participants were included in the study if they were 55 years or older, had a good comprehension of the Dutch language, were mobile enough to travel independently to the research center, were not using psychotropic medication on a daily basis, and had not previously participated in a neuropsychological research program. Exclusion criteria were a score below 24 on the Mini-Mental State Examination (MMSE) [26], a diagnosis of central nervous system pathology, or a major psychiatric disorder.

The Medical Ethics Committee of the University Hospital Maastricht approved the protocol and all participants gave informed consent.

\subsection{Intervention}

\subsubsection{Collective training}

The memory-training program was developed by Ponds and Bouwens [27] and taught by experienced teachers of the service center of the home care organization Groene Kruis Heuvelland in Maastricht, The Netherlands. The program was developed to increase knowledge of normal memory functioning and normal memory decline with aging, and to promote insight into one's memory functioning. The maximum number of participants per group was 12 , to ensure that the training group could function optimally, and for logistic reasons. The training was administered in eight 2-h sessions, one session a week. Each session was structured: homework and last week's theme were discussed first and then the new theme or topic was introduced. All themes were illustrated with practical assignments. The themes involved were: shortand long-term memory, storage and retrieval of information, age-related decline in memory functioning, differences between normal memory functioning and dementia, memory self-efficacy, the relation between memory functioning and physical and psychological health, and internal and external memory strategies. All topics were discussed briefly in the last session. All participants received a reader.

\subsubsection{Individual training}

The Dutch book 'Geheugensteun' ('Memory Support') [28] covers the same content in the same order as the above described memory-training program. All themes discussed in the collective memory-training sessions are also extensively described in the book. The memory-training book differed from the collective training program in that there were fewer practical assignments and homework and subjects had to study on their own. To facilitate and motivate this self-study, all subjects were given a study schedule, and after 4 weeks they were telephoned to ask them if they were on schedule with their reading and if they had any questions about the book.

\subsection{Measures}

The outcome variables were obtained from a test battery that included subjective and objective memory tests to measure memory functioning before and immediately after the intervention and 4 months later. All measures were administered by trained assistants who were not involved in the memory training.

\subsubsection{Objective memory tests}

The Visual Verbal Learning Test (VVLT) [29] is a verbal memory task to measure the ability to learn new verbal information and retrieve information from memory. Fifteen low-associative words are presented to the subject five times. After each presentation the subject is asked to recall as many words as possible, with no restriction concerning the order of recall (immediate recall). The maximum score that can be obtained after five successive trails is 75 . Twenty minutes after the last presentation the subject is again requested to recall as many correct words as possible (delayed recall). Parallel versions of the memory task were used for each assessment. 
The short-story test [30,31] is a Dutch memory task to measure storage of logical information. Participants are handed out a page of carefully constructed prose. After reading the story out aloud, the subjects are given $3 \mathrm{~min}$ to study the story, and then they are asked to tell as much as possible about the story in their own words (immediate recall) and again $15 \mathrm{~min}$ later (delayed recall). The maximum score is 38 . Parallel versions of the story were used for each assessment.

\subsubsection{Subjective memory tests}

Three scales of the abridged Metamemory in Adulthood (MIA) questionnaire [32] were used to evaluate subjective memory functioning. Participants are asked to rate statements on a 5-point Likert scale (strongly agree, agree, undecided, disagree, strongly disagree). The Capacity scale consists of 12 items and higher scores indicate more perceived memory capacity (e.g. 'I am good at remembering birthdays'). The Change scale has 10 items and a higher score indicates less perceived decline or more stability in memory functioning (e.g. 'I am less efficient at remembering things now than I used to be'). The Anxiety scale includes 12 items and a higher score reflects more feelings of anxiety and stress in relation to memory functioning (e.g. 'I get anxious when I am asked to remember something'). The three scales, Capacity, Change, and Anxiety together form the factor 'Memory Self-Efficacy' (MSE) and higher scores indicate a higher MSE level.

The Cognitive Failure Questionnaire (CFQ) [33] is validated for and adapted to the Dutch population [2,34]. The questionnaire consists of 25 items measuring the frequency of everyday cognitive 'failures' in the area of memory, attention, perception, and action. Participants are asked to indicate on a 5-point scale how often they usually experience each particular cognitive failure (never, very rarely, occasionally, quite often, and very often). A higher score on the $\mathrm{CFQ}$ indicates more cognitive failure.

\subsubsection{Other variables}

Four subtasks of the Groninger Intelligence Test (GIT) [35] were used to make a reliable estimation of IQ. The four subtasks involved were: the correct completion of as many addition sums as possible in $1 \mathrm{~min}$, indicating which of the five alternative words is exactly synonymous with a given word, indicating which two-dimensional shapes from a larger set are needed to exactly fill up a given space, and indicating which of five alternatives is related in the same way to a given word as two words in an example.

The Mini-Mental State Examination [26] was used as a screening instrument for dementia, and consists of the subscales orientation, registration, recall, attention, language, and construction. A maximum score of 30 can be obtained.

Level of education (1-8) was scored as follows: 1 = primary education, $2=$ lower vocational education, 3 = intermediate general secondary education, 4 $=$ intermediate vocational education, $5=$ higher general secondary education/university preparatory education, 6 $=$ higher vocational preparatory education, $7=$ higher professional education, and $8=$ university education [36].

\subsection{Procedures}

The design was a randomized controlled trial with two follow-up measurements. All groups were neuropsychologically tested four times; two pre-test assessments (double baseline, with 1 week in between), a post-test (at 9 weeks, 1 week after completion of the intervention program), and a follow-up assessment (4 months after the intervention). The main reason for using a double baseline was to administer the VVLT two times, in order to minimize learning and procedure-learning effects. Therefore, all the statistical analyses were performed using data for the second baseline assessment and the two subsequent follow-up measurements. The same test battery and questionnaires were administered before treatment (second baseline), at the 1-week follow-up and at the 4-month follow-up. All neuropsychological tests were administered in the same order on all test occasions.

Participants were randomly assigned to a collective memory-training program, an individual memory-training program, or a control group. The method of randomization was a block design with block size three, and with stratification for sex. The investigators responsible for randomization were not involved in the training procedures. To avoid contamination, couples were always assigned to the same condition.

\subsection{Statistical analysis}

All statistical analyses were performed using SPSS for Macintosh, version 10 (SPSS-Inc., Chicago).

Although individuals were randomly assigned to the three conditions, differences in baseline characteristics between the three groups were examined. Separate One-way Analyses of Variance (ANOVA) were performed for age, educational level, intelligence, and MMSE scores. A Chi-square test was used to analyze the variables sex and marital status (married or cohabiting versus others).

General Linear Model (GLM) repeated measures analysis of variance was carried out to examine the effect of the interventions on memory performance. Analyses were performed with group as the between-subjects variable and memory performance on the first and second follow-up phase as the within-subjects factor. Contrasts were defined to compare performance of the three groups over time. In these analyses, age, sex, educational level, and baseline scores were treated as covariates. Baseline scores were treated as covariates in this model to control for baseline group differences, which were present in one of the outcome variables. Because comparisons were made between more than two groups, estimated effects sizes were defined with partial Eta-squared values $\left(\eta^{2}\right)$. Consistent with the rules for clinical trails, all analyses were based on the groups as randomized, accord- 


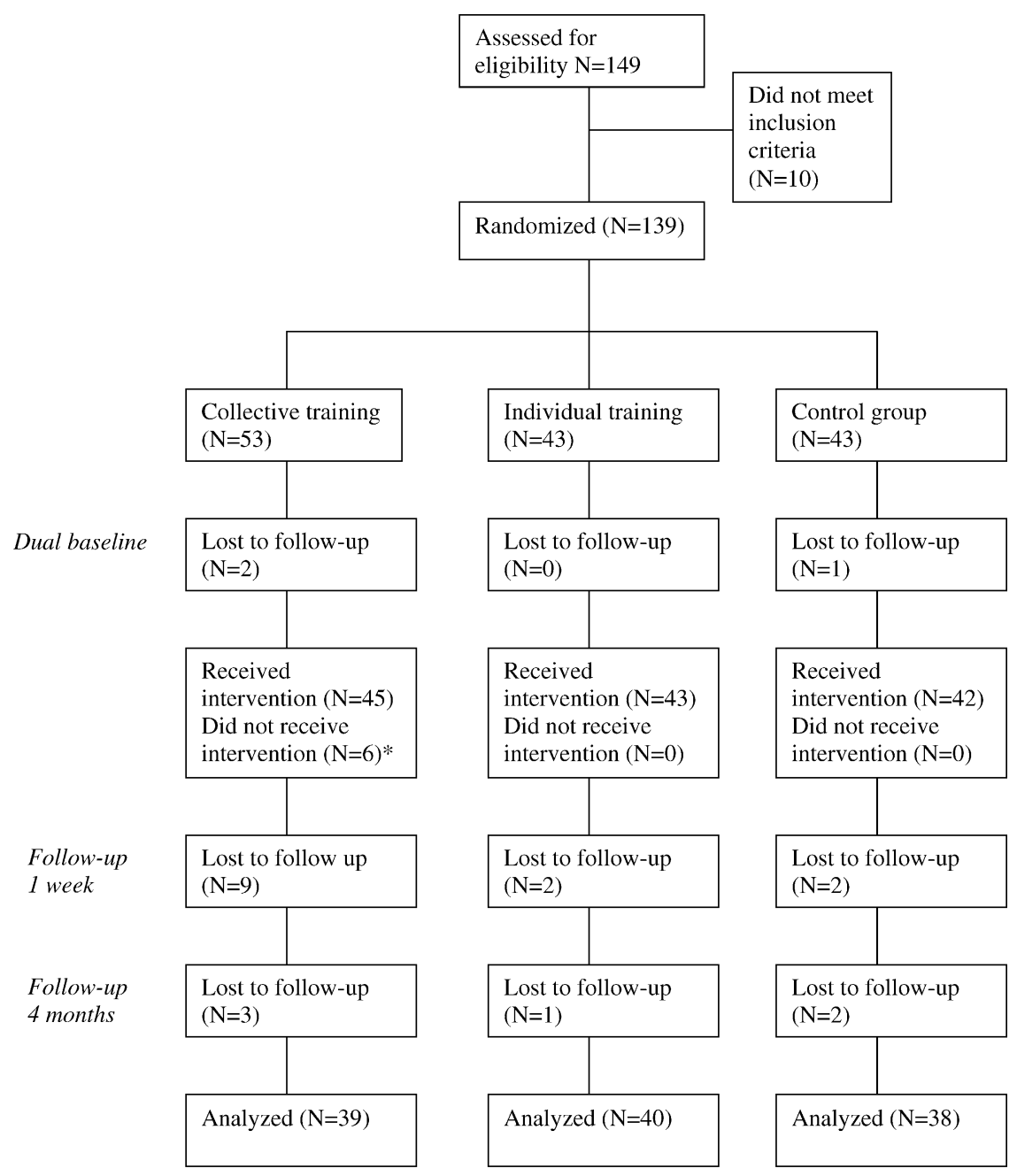

* Analyzed as randomized

Fig. 1. Flowchart of participants.

ing to the principle of 'intention-to-treat' [37]. In addition, results of analyses with data for subjects who actually completed the intervention are also reported.

\section{Results}

\subsection{Recruitment}

One hundred and forty-nine individuals were willing to participate. Ten participants did not meet the inclusion criteria and were excluded from participation, seven participants with a MMSE score below 24, and three participants who previously participated in a neuropsychological research program. The 139 elderly individuals who met the inclusion criteria were randomly assigned to one of three groups: a collective training group $(N=53)$, an individual training group $(N=43)$, or a control group $(N=43)$. In total, $136(97.8 \%)$ people completed the assessment before the intervention, $123(88.5 \%)$ persons completed the 1-week follow-up, and 117 (84.2\%) participants completed the whole study. Twenty-two people dropped out the study, 14 of them were originally assigned to the collective training group, 3 to the individual training group, and 5 to the control group. The number of dropouts was significantly higher in the collective training group $(P=0.02)$. Results of recruitment and randomization are given in Fig. 1.

\subsection{Baseline background characteristics}

There were no significant differences between the three groups in age, marital status, intelligence, education, and MMSE score. Demographic characteristics and mean MMSE and IQ scores are summarized in Table 1.

In addition, the three groups were compared with respect to the number of self-reported life events, the number of illnesses reported on a morbidity checklist, whether or not participants ever suffered from concussion, or had been under general anaesthesia, and their levels of depressive and 
Table 1

Means and standard deviations for demographic variables in each study group (total $N=139$ )

\begin{tabular}{|c|c|c|c|c|}
\hline & $\begin{array}{l}\text { Collective training } \\
(N=53)\end{array}$ & $\begin{array}{l}\text { Individual training } \\
(N=43)\end{array}$ & $\begin{array}{l}\text { Control group } \\
(N=43)\end{array}$ & $P$ value \\
\hline Age & $69.32(7.77)$ & $68.07(6.58)$ & $68.30(8.03)$ & 0.681 \\
\hline Marital status (\% married/living together) & 60 & 53 & 72 & 0.491 \\
\hline Gender (\% women) & 70 & 63 & 63 & 0.699 \\
\hline Education & $3.83(1.96)$ & $3.74(1.84)$ & $3.86(2.24)$ & 0.962 \\
\hline IQ & $118.88(13.37)$ & $122.51(11.62)$ & $122.40(11.46)$ & 0.257 \\
\hline MMSE & $28.72(1.26)$ & $28.77(1.48)$ & $28.49(1.74)$ & 0.647 \\
\hline
\end{tabular}

MMSE: Mini-Mental State Examination.

anxiety symptoms, measured with the subscales Depression and Anxiety of the Symptom Checklist-90 (SCL-90) [38]. No differences were found between the three groups on any of these variables (not tabulated).

\subsection{Objective memory performance}

The collective training group had better performance scores than the individual training group or the control group on the delayed recall task of the VVLT $(F(2,109)$ $=7.584, P=0.001)$. Significant contrasts were found between the group training condition and the other two groups, indicating that over time, the subjects who received the collective training intervention were better able to remember a previously learned word list. The estimated effect size $\left(\eta^{2}\right)$ was 0.122 . No interactions were found, suggesting that no change in intervention effect took place from 1 week to 4 months follow-up. This was confirmed using univariate analyses of variance on the second follow-up, were a significant effect was found for group training condition $(F(2$, 109) $=6.634, P=0.002$ ).

Main effects of group membership on the other objective outcome variables were not statistically significant (see Table 2).

Table 2

Means, standard deviations, and results of tests for group differences of the objective test performances

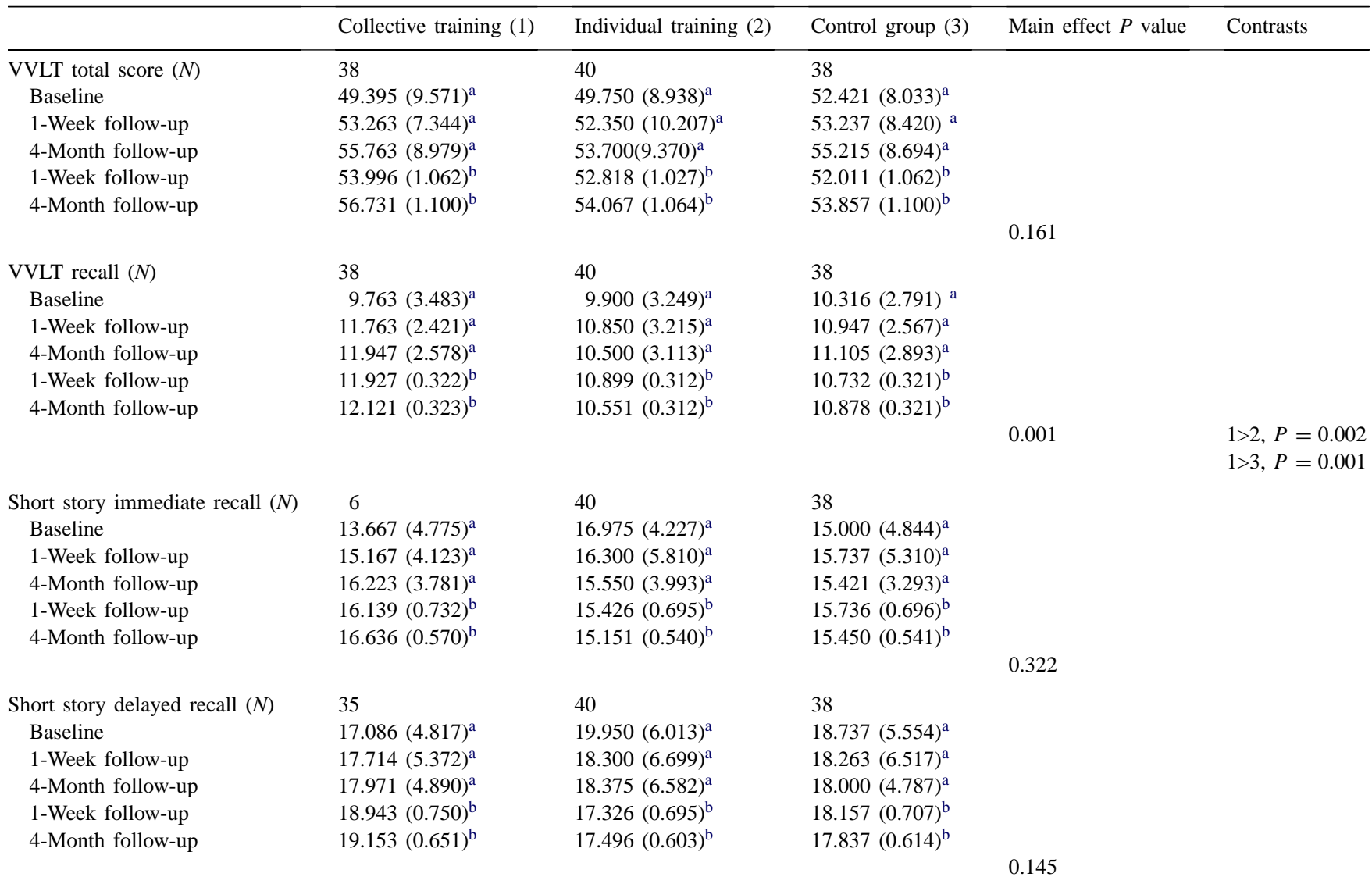

${ }^{*} P$ values are interpreted as the results of comparison between the different groups. VVLT: Visual Verbal Learning Test.

${ }^{a}$ Unadjusted mean scores and standard deviations.

${ }^{\mathrm{b}}$ Mean scores and standard errors adjusted for age, gender, educational level, and baseline scores. 
Table 3

Means, standard deviations, and results of tests for group differences of the subjective test performances

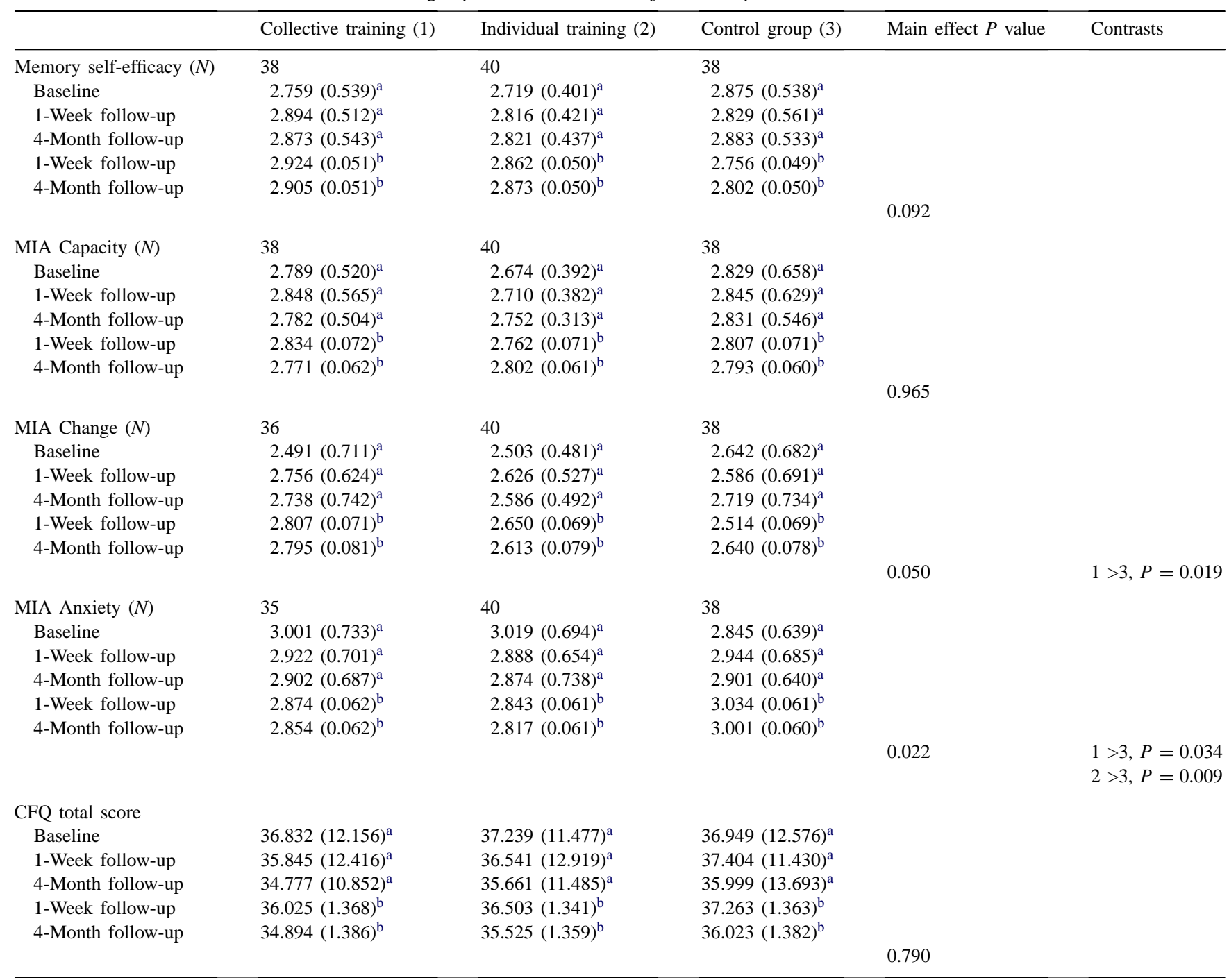

${ }^{*} P$ values are interpreted as the results of comparison between the different groups. MIA: Metamemory in Adulthood questionnaire, CFQ: Cognitive Failure Questionnaire.

${ }^{\mathrm{a}}$ Unadjusted mean scores and standard deviations.

${ }^{\mathrm{b}}$ Mean scores and standard errors, adjusted for age, gender, educational level, and baseline scores.

\subsection{Subjective memory performance}

A significant main effect was found for group membership on the MIA scale Change $(F(2,98)=3.089, P=0.050)$, estimated effect size $\left(\eta^{2}\right)$ was 0.059 , with a significant contrast between the collective training group and the control group (see Table 3). After the intervention the collective training group reported more feelings of stability concerning memory functioning, as compared to the control group. In addition, a main effect of group membership was found on the Anxiety scale of the MIA $(F(2,98)=3.986, P=0.022)$. The estimated effect size $\left(\eta^{2}\right)$ was 0.075 . Significant contrasts were found between the collective training group and the control group and between the individual training group and the control group, indicating that over time both intervention groups showed a consistent decrease in stress and anxi- ety in memory related situations, as compared to the control group. Main effects of group membership on the other subjective outcome variables were not statistically significant.

\subsection{Compliance}

Data were analyzed separately for participants who completed the intervention. In the collective training group, non-compliance was defined as attendance of five or fewer sessions. In the individual training group, non-compliance was defined as the inability to answer correctly 7 of 11 statements (true or false) about the content of the book and the inability to name at least three memory strategies, discussed in the book. In the collective training group, six people decided not to start with the intervention, but stayed in the study and provided follow-up data. Nine participants 
discontinued the intervention and were lost to follow-up, but they had already been excluded from analyses. In the individual training group, three participants were considered non-compliant, but did provide follow-up data. Main reasons for not completing the training course or not reading the book were being too busy with other activities or work, having no transport to the training center, health-related problems, or family circumstances.

When the analyses were restricted to compliant participants only, the results were similar, except that effects became more robust. For example, an additional small effect on the total score of the $\operatorname{VVLT}(F(2,100)=2.639, P=0.076)$ was found with a significant contrast between the collective training group and the control group.

\section{Discussion and conclusion}

\subsection{Discussion}

The main objective of this study was to compare the effect of two types of memory-training interventions, relative to a waiting-list control. Outcome variables were both subjective and objective memory functioning. After the intervention, participants in the collective memory-training group reported more stability in memory functioning and had fewer feelings of anxiety and stress in relation to memory functioning. In addition, positive effects were found in objective memory functioning. Compared with the other two groups, the collective training group had an improved recall of a previously learned word list. However, no effects were found on the logical memory test. A possible explanation for the absence of intervention effects on the latter test is differences in test reliability [39]. In contrast, a positive effect of the intervention in the individual training group was only found on the Anxiety scale of the MIA. This contrasts with reports of the effectiveness of self-taught training in improving memory performance and memory knowledge [25] and with reports that individual training is as effective as group training $[24,40]$. However, our findings are consistent with other studies showing that the gain of an intervention is maximal when participants can benefit from the comforting and motivating effect of sharing their concerns about memory with others $[22,41]$. Since the elderly participants in the individual training program received the same information as those in the collective memory-training group, this group effect is apparently considerable. Bandura [42] also pointed out that vicarious observation and social influences or persuasions are important sources of self-efficacy, and these sources are provided by group participation. A second important difference is that in the collective training program all themes that were discussed were illustrated with practical examples, so participants had the opportunity to practice the new information.

Attrition and compliance appeared to be selective in this study, in that most of the dropouts were originally assigned to the collective training group. This indicates that motivational factors contribute significantly to a successful intervention. This conclusion is supported by the observation that when the analyses were restricted to compliant participants, effects became more robust, even when as a result of this procedure the power of the overall test was reduced. Participants in this study already had an above average performance on memory tests at baseline, and were intelligent, healthy and particularly interested in memory functioning. We compared the performance on the VVLT of the participants in this study with the performance of elderly subjects who participated in the Maastricht Aging Study (MAAS), a longitudinal study on normal cognitive aging [43-45]. Participants in our study outperformed elderly subjects who were enrolled in the MAAS study in terms of the total score and the recall score of the VVLT, after matching for sex, age, and education. However, compared with elderly people in the MAAS, the participants in the current study were less confident about the effectiveness of their own memory, reported more perceived decline, and had more feelings of anxiety and stress in relation to memory functioning [2]. This indicates that the participants of our study may belong to a sub-population of elderly people, with a relatively normal functioning but who do have complaints and who are willing to invest time and effort in an intervention. This may be an important finding because it suggests that there are elderly who would like to participate in an intervention, possibly in the expectation that training may help prevent an incipient decline of cognitive functioning. A follow-up study is warranted to learn more about the characteristics of this group of elderly individuals and the determinants of success of the training. These findings also have implications for the maximal results that can be obtained with the training program. Because our participants were already functioning at a relatively high level at baseline, intervention gains could possibly be more difficult to detect. However, previous studies have found that individuals who tend to benefit the most from interventions are the ones who are younger and have better cognitive functions at baseline [22,46,47], although others did not confirm these findings [39,48-50].

\subsection{Conclusion}

Although effects were relatively small and were not found for all outcome variables, the overall pattern of results suggests that the collective variant of this training program is effective in improving subjective and objective memory performance.

\subsection{Practice implications}

Taking into account the time, effort, and costs associated with the intervention, we consider the program a valuable contribution to public health interventions for older adults. Our conclusions were based on between-group comparisons. In individual cases there may be even more substantial inter- 
vention effects. This makes it potentially important to find out whether particular variables can predict maximal treatment outcome. Results suggest that the program is most likely to be effective in people who have the time, the opportunity and the motivation to participate in a memory-training program. It is conceivable that the intervention would have more beneficial effects in more selected groups of participants, such as elderly individuals with more pronounced memory complaints, or patients who have been referred to a memory clinic. A follow-up study is being planned to test this notion in more detail.

\section{Acknowledgements}

The study was conducted in close collaboration with Annemarie Zeelen, Lilian Houben, and Mirjam Notermans of the Groene Kruis Service. We also thank Janneke Spauwen, Jaimie Luermans, and Rubia Bloo for assistance in neuropsychological testing. The Dutch Research Council funded this study (NWO: 014-91-047).

\section{References}

[1] Cutler SJ, Grams AE. Correlates of self-reported everyday memory problems. J Gerontol B Psychol Sci Soc Sci 1988;43:82-90.

[2] Ponds RWHM. Forgetfulness and cognitive aging: prevalence, characteristics, and determinants. Thesis. Maastricht University; 1998.

[3] Dik MG, Jonker C, Comijs HC, et al. Memory complaints and APOE-epsilon 4 accelerate cognitive decline in cognitively normal elderly. Neurology 2001;57:2217-22.

[4] Jonker C, Geerlings MI, Schmand B. Are memory complaints predictive for dementia? A review of clinical and population-based studies. Int J Geriatr Psychiatry 2000;15:983-91.

[5] Jorm AF, Christensen H, Korten AE, Jacomb PA, Henderson AS. Memory complaints as a precursor of memory impairment in older people: a longitudinal analysis over 7-8 years. Psychol Med 2001;31:441-9.

[6] Derouesne C, Lacomblez L, Thibault S, LePoncin M. Memory complaints in young and elderly subjects. Int J Geriatr Psychiatry 1999;14:291-301.

[7] Birren JE, Schaie KWE. Handbook of the Psychology of Aging. San Diego: Academic Press; 1996.

[8] Bolla KI, Lindgren KN, Bonaccorsy C, Bleecker ML. Memory complaints in older adults. Fact or fiction? Arch Neurol 1991;48:61-4.

[9] Commisaris CJAM, Ponds RWHM, Jolles J. Subjective forgetfulness in a normal Dutch population: possibilities for health education and other interventions. Pat Educ Couns 1998;34:25-32.

[10] Comijs HC, Deeg DJ, Dik MG, Twisk JW, Jonker C. Memory complaints; the association with psycho-affective and health problems and the role of personality characteristics. A 6-year follow-up study. J Affect Disord 2002;72:157-65.

[11] Stevens FCJ, Kaplan CD, Ponds RWHM, Jolles J. The importance of active lifestyles for memory performance and memory self-knowledge. Basic Appl Soc Psychol 2001;23:137-45.

[12] Clarnette RM, Almeida OP, Forstl H, Paton A, Martins RN. Clinical characteristics of individuals with subjective memory loss in Western Australia: results from a cross-sectional survey. Int J Geriatr Psychiatry 2001;16:168-74.

[13] Jolles J, van Boxtel MP, Ponds RW, Metsemakers JF, Houx PJ. The Maastricht aging study (MAAS). The longitudinal perspective of cognitive aging. Tijdschr Gerontol Geriatr 1998;29:120-9.
[14] Dixon RA. Questionnaire research on metamemory and aging: issues of structure and function. In: Poon LW, Rubin DC, Wilson BA, editors. Everyday cognition in adulthood and late life. Cambridge: Cambridge University Press; 1989. p. 394-415.

[15] Levy-Cushman J, Abeles N. Memory complaints in the able elderly. Clin Gerontol 1998;19:3-24.

[16] Cavenaugh JC. Memory self-efficacy as a moderator of memory change. In: Blanchard-Fields F, Hess TH, editors. Perspectives on cognitive change in adulthood and aging. New York: The McGraw-Hill Companies; 1996. p. 488-507.

[17] Lovelace EA. Aging and metacognitions concerning memory function. In: Lovelace EA, editor. Aging and cognition: mental processes, self awareness and interventions. Amsterdam, The Netherlands: Elsevier Science; 1990. p. 157-188.

[18] Berry JM, West RL. Cognitive self-efficacy in relation to personal mastery and goal setting across the life span. Int $\mathrm{J}$ Behav Dev 1993;16:351-79.

[19] Ponds RWHM, Jolles J. Memory complaints in elderly people: the role of memory abilities, metamemory, depression, and personality. Educ Gerontol 1996;22:341-57.

[20] Commissaris CJAM. Voorlichting over geheugenproblemen en dementie [Education about memory problems and dementia]. Thesis. Maastricht University; 1993.

[21] Floyd M, Scogin F. Effects of memory training on the subjective memory functioning and mental health of older adults: a meta-analysis. Psychol Aging 1997;12:150-61.

[22] Verhaeghen P, Marcoen A, Goossens L. Improving memory performance in the aged through mnemonic training: a meta-analytic study. Psychol Aging 1992;7:242-51.

[23] Andrewes DG, Kinsella G, Murphy M. Using a memory handbook to improve everyday memory in community-based older adults with memory complaints. Exp Aging Res 1996;22:305-22.

[24] Scogin F, Prohaska M, Weeks E. The comparative efficacy of self-taught and group memory training for older adults. J Clin Geropsychol 1998;4:301-14.

[25] Woolverton M, Scogin F, Shackelford J, Black S, Duke L. Problem-targeted memory training for older adults. Aging Neuropsychol Cogn 2001;8:241-55.

[26] Folstein MF, Folstein SE, McHugh PR. Mini-mental state: a practical method for grading the cognitive state of patients for the clinician. J Psychiatry Res 1975;12:189-98.

[27] Ponds RWHM, Bouwens MRJ. Geheugencursus voor ouderen [Memory course for older individuals]. Den Bosch: Gezondheid Service Nederland; 1997.

[28] Ponds R, V.F. Geheugensteun [Memory support]. Utrecht/Antwerpen: Kosmos-Z\&K Uitgevers; 2000.

[29] Brand N, Jolles J. Learning and retrieval rate of words presented auditorily and visually. J Gen Psychol 1985;112:201-10.

[30] Bouma JM, Lindenboom J, van Houte L. Klinische neuropsychologische assessment: een handleiding voor de praktijk [Clinical neuropsychological assessment: a guide for practice]. In: Amsterdam U, editor. Amsterdam; 1990.

[31] Niehof J. Validering van een zestal logical memory taken [Validity of six logical memory tasks]. Groningen: University of Groningen; 1995.

[32] Ponds RWHM, Jolles J. The abridged Dutch metamemory in adulthood (MIA) questionnaire: structure, and effects of age, sex, and education. Psychol Aging 1996;11:324-32.

[33] Broadbent DE, Cooper PF, FitzGerald P, Parkes KR. The cognitive failure questionnaire (CFQ) and its correlates. Br J Clin Psychol 1982;21:1-16.

[34] Merckelbach H, Muris P, Nijman H, de Jong P. Self-reported cognitive failures and neurotic symptomatology. Pers Indiv Differ 1996;20:715-24.

[35] Luteijn F, van der Ploeg FAE. Handleiding Groninger Intelligentietest (GIT) [Manual Groningen intelligence test]. Lisse, The Netherlands: Swets and Zeitlinger; 1983. 
[36] De Bie SE. Standaardvragen 1987: voorstellen voor uniformereing van vraagstelligen naar achtergrondkenmerken en interviews [Standard questions 1987: proposal for uniformization of questions regarding background variables and interviews]. 2nd ed. Leiden: Leiden University Press; 1987.

[37] Altman DG. Practical statistics for medical research. London: Chapman \& Hall; 1991.

[38] Derogatis LR. SCL-90: administration, scoring and procedures manual-I for the revised version. Baltimore: Johns Hopkins School of Medicine, Clinical Psychometrics Research Unit; 1977.

[39] Lezak MD. Neuropsychological assessment. New York: Oxford University Press; 1995

[40] Rasmusson DX, Rebok GW, Bylsma FW, Brandt J. Effects of three types of memory training in normal elderly. Aging Neuropsychol Cogn 1999;6:56-66.

[41] Flynn TM, Storandt M. Supplemental group discussions in memory training for older adults. Psychol Aging 1990;5:178-81.

[42] Bandura A. Regulation of cognitive processes through perceived self-efficacy. Dev Psychol 1989;25:729-35.

[43] Jolles J, Houx PJ, van Boxtel MPJ, Ponds RWHM. Maastricht aging study: determinants of cognitive aging. Maastricht: Neuropsych Publishers; 1995.
[44] Dijkstra JB, Van Boxtel MP, Houx PJ, Jolles J. An operation under general anesthesia as a risk factor for age-related cognitive decline: results from a large cross-sectional population study. J Am Geriatr Soc 1998;46:1258-65.

[45] van Boxtel MP, Gaillard C, Houx PJ, Buntinx F, de Leeuw PW, Jolles $\mathrm{J}$. Is nondipping in $24 \mathrm{~h}$ ambulatory blood pressure related to cognitive dysfunction? J Hypertens 1998;16:1425-32.

[46] Kliegl R, Smith J, Baltes PB. On the locus and process of magnification of age differences during mnemonic training. Dev Psychol 1990;6:894-904.

[47] Hill RD, Yesavage JA, Seikh J, Friedman L. Mental status as a predictor of response to memory training in older adults. Educ Gerontol 1989;15:633-9.

[48] Cavallini E, Pagnin A, Vecchi T. Aging and everyday memory: the beneficial effect of memory training. Arch Gerontol Geriatr 2003;37:241-57.

[49] Brooks 3rd JO, Friedman L, Pearman AM, Gray C, Yesavage JA. Mnemonic training in older adults: effects of age, length of training, and type of cognitive pretraining. Int Psychogeriatr 1999;11:75-84.

[50] Mohs RC, Ashman TA, Jantzen K, et al. A study of the efficacy of a comprehensive memory enhancement program in healthy elderly persons. Psychiatry Res 1998;77:183-95. 